\title{
Clinical and genetic features of Spanish patients with Mevalonate kinase deficiency
}

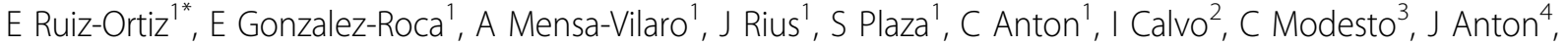

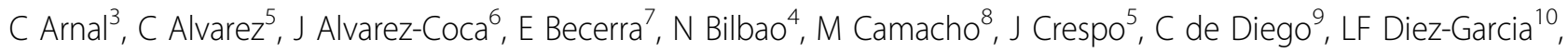 \\ L Espinosa $^{11}$, D Garcia-Escriva ${ }^{12}$, F de Gracia ${ }^{13}$, Ml Gonzalez $^{2}$, E Iglesias $^{4}$, S Izquierdo $^{14}$, B Lastra $^{15}$, P Llobet ${ }^{16}$, \\ B Lopez ${ }^{2}$, V Lopez-Gonzalez ${ }^{17}$, R Martinez ${ }^{18}$, MA Martin-Mateos ${ }^{4}$, R Merino $^{11}$, L Ortega ${ }^{19}$, ME Peiro ${ }^{5}$, \\ I Perez de Soto ${ }^{8}$, C Perez-Mendez ${ }^{20}$, V Rodriguez-Valverde ${ }^{5}$, A Ribes ${ }^{1}$, A Ruiz ${ }^{21}$, B Sanchez ${ }^{8}$, JL Santos ${ }^{19}$, B Sevilla ${ }^{22}$, \\ J Sotoca ${ }^{23}$, J Vilas ${ }^{24}$, A Villoria ${ }^{25}$, J Yagüe ${ }^{1}$, Jl Arostegui ${ }^{1}$ \\ From 8th International Congress of Familial Mediterranean Fever and Systemic Autoinflammatory Diseases \\ Dresden, Germany. 30 September - 3 October 2015
}

\section{Introduction}

Mevalonate kinase deficiency (MKD) is a recessivelyinherited autoinflammatory condition caused by loss-offunction $M V K$ mutations. This gene encodes for the enzyme mevalonate kinase (MVK), which catalyzes a crucial step of the biosynthetic pathway of cholesterol and isoprenoids. The partial deficiency of enzymatic activity causes the Hyper-IgD and periodic fever syndrome (HIDS), whereas it complete deficiency provokes the Mevalonic Aciduria (MA).

\section{Objectives}

The aim of this study was to describe the clinical and genetic features of Spanish patients with MKD diagnosed during the past 15 years.

\section{Methods}

The patients' data as well as the outcome of the administered treatments were collected from charts reviews. $M V K$ analysis was performed by Sanger-based sequencing.

\section{Results}

Forty-one patients from different Spanish hospitals were included. Thirty-eight patients (92.7\%) suffered from HIDS and three patients (7.3\%) from MA. The MKD diagnosis was established in all of them by the detection of biallelic $M V K$ mutations. Eighteen different $M V K$ mutations were detected, with the p.[(V377I)] and p.[(I268T)] mutations as the most prevalent, accounting for $54.9 \%$ and

${ }^{1}$ Hospital Clinic, Barcelona, Spain

Full list of author information is available at the end of the article
$26.8 \%$ of mutated alleles, respectively. The majority of these mutations (96.4\%) were missense mutations. The remainder mutations included premature stop (1.2\%), frameshift (1.2\%), and splice site mutations (1.2\%). In the group of patients with HIDS (n: 38), twelve patients (31.6\%) carried homozygous genotypes and twenty-six patients (68.4\%) compound heterozygous genotypes. In the group of HIDS patients with homozygous genotypes $(n=12)$, ten patients $(83.3 \%)$ carried the p.[(V377I)]; [(V377I)] genotype. By contrast, in the group of patients with MA only one patient (33.3\%) carried a homozygous genotype (the p.[(I268T)];[(I268T)]).

From a clinical point of view, the median age at the disease onset was 6 months (range 0-408), and the median duration of flares was 4.8 days (range 2-17.5). Mandatory vaccinations were identified as triggering factors for acute episodes in eleven patients (26.8\%). The most prevalent manifestations during inflammatory episodes were fever (80.5\%), lymphadenopathies (70.7\%), abdominal pain $(63.4 \%)$, diarrhea (58.5\%), aphthous ulcers (53.7\%) and arthralgia (51.2\%). AA amyloidosis was only detected in one patient $(2.4 \%)$, but had a severe course.

\section{Conclusion}

We herein provide a detailed description of the clinical and genetic features of a Spanish cohort of MKD patients carrying biallelic $M V K$ mutations. Most of patients suffered from the mild MKD phenotype, the HIDS syndrome. Two prevalent $M V K$ mutations, p.[(V377I)] and p.[(I268T)], were found in our cohort, and fever and lymphadenopathies were the most common features in enrolled patients. 


\section{Authors' details}

${ }^{1}$ Hospital Clinic, Barcelona, Spain. ${ }^{2}$ Hospital La Fe, Valencia, Spain. ${ }^{3}$ Hospital Vall Hebron, Barcelona, Spain. ${ }^{4}$ Hospital Sant Joan De Deu, Barcelona, Spain. ${ }^{5}$ Hospital Marques De Valdecilla, Santander, Spain. ${ }^{6}$ Hospital Del Niño Jesus, Madrid, Spain. ${ }^{7}$ Hospital Universitario De Torrevieja, Alicante, Spain. ${ }^{8}$ Hospital Virgen Del Rocío, Sevilla, Spain. ${ }^{9}$ Hospital Virgen De La Salud, Toledo, Spain. ${ }^{10}$ Complejo Hospitalario Torrecárdenas, Almeria, Spain. ${ }^{11}$ Hospital La Paz, Madrid, Spain. ${ }^{12}$ Hospital General De Valencia, Valencia, Spain. ${ }^{13}$ Hospital Virgen De La Luz, Cuenca, Spain. ${ }^{14}$ Hospital Miguel Servet, Zaragoza, Spain. ${ }^{15}$ Hospital Central De Asturias, Oviedo, Spain. ${ }^{16}$ Hospital De Granollers, Barcelona, Spain. ${ }^{17}$ Hospital Universitario Virgen De La Arrixaca, Murcia, Spain. ${ }^{18} \mathrm{Complexo}$ Hospitalario Universitario De Ourense, Ourense, Spain. ${ }^{19} \mathrm{Hospital}$ Universitario Virgen De Las Nieves, Granada, Spain. ${ }^{20}$ Hospital De Cabueñes, Gijon, Spain. ${ }^{21}$ Hospital Son Espases, Mallorca, Spain. ${ }^{22}$ Hospital San Cecilio, Granada, Spain. ${ }^{23}$ Complejo Hospitalario Universitario De Albacete, Albacete, Spain. ${ }^{24}$ Hospital De Pontevedra, Pontevedra, Spain. ${ }^{25}$ Corporació Parc Taulí, Barcelona, Spain

Published: 28 September 2015

doi:10.1186/1546-0096-13-S1-P36

Cite this article as: Ruiz-Ortiz et al: Clinical and genetic features of Spanish patients with Mevalonate kinase deficiency. Pediatric Rheumatology 2015 13(Suppl 1):P36.

\section{Submit your next manuscript to BioMed Central and take full advantage of:}

- Convenient online submission

- Thorough peer review

- No space constraints or color figure charges

- Immediate publication on acceptance

- Inclusion in PubMed, CAS, Scopus and Google Scholar

- Research which is freely available for redistribution

Submit your manuscript at www.biomedcentral.com/submit 